\title{
Agalliana Oman, 1933 (Hemiptera, Cicadellidae, Agalliinae): descrições de três novas espécies ${ }^{1}$
}

\author{
Kellin Cristina Kropzak Schmoeller ${ }^{2,3}$ \\ Keti Maria Rocha Zanol ${ }^{2,4}$
}

Abstract. Agalliana Oman, 1933 (Hemiptera, Cicadellidae, Agalliinae): descriptions of three new species. Agalliana goianensis sp. nov., Agalliana alutacea sp. nov., Agalliana truncata sp. nov., all from Brazil, are described.

KeYwords. Agalliana; Agalliinae; Cicadellidae; Hemiptera.

\section{INTRODUÇÃO}

Oman (1933) descreveu o gênero Agalliana designando Bythoscopus sticticollis Stal, 1859 como espécie-tipo. O gênero possui, atualmente, seis espécies com distribuição basicamente sul-americana com exceção de $A$. sticticollis que alcança o Caribe.

As características genéricas são: cabeça curta, de comprimento uniforme. Sutura coronal ausente. Ocelos na face. Distância entre os ocelos maior do que a distância entre o ocelo e o olho. Anteclípeo com ápice arredondado excedendo as margens das lora. Superfície do pronoto com pontuações. Tégminas semitransparentes, com três células anteapicais fechadas e quatro células apicais. Pigóforo sem macrocerdas, com um par de espinhos dorsal. Valva genital fundida com as placas subgenitais. Placas subgenitais triangulares, mais curtas que o pigóforo; sem macrocerdas. Estilos forquilhados. Edeago simétrico.

O material está depositado na Coleção de Entomologia Pe J. S. Moure, Departamento de Zoologia, Universidade Federal do Paraná, Curitiba (DZUP).

\section{Agalliana goianensis sp. nov.}

(Figs. 1-9)

Holótipo macho. Coroa fulva com quatro manchas e duas faixas longitudinais pretas. Face fulva. Frontoclípeo ornado de preto. Anteclípeo com uma mancha triangular e contorno pretos. Lora com áreas pretas. Genas com uma mancha preta contornando os alvéolos antenais.

Pronoto fulvo; margem anterior com duas manchas, de contorno irregular, pretas; disco com uma faixa longitudinal mediana e duas manchas arredondadas, pretas; pontuações pretas. Escutelo preto com quatro manchas arredondadas amarelas.

Tégminas marrom-claras. Venação marrom. Clavo com uma mancha longitudinal marrom entre a $1 \mathrm{~A}$ e a sutura claval. Margem anal com áreas marrons.

Pigóforo sem cerdas; espinho dorsal, visto de cima, expandido de forma mais ou menos triangular; borda interna serrilhada. Placas subgenitais com ápice arredondado. Edeago sem apêndices.

Fêmea. Coroa com as faixas longitudinais e as manchas, próximas aos olhos, marrom-claras. Frontoclípeo ornado de preto e marrom-claro. Sétimo esterno mais largo do que longo, com uma pequena fenda mediana; margem posterior, lateral à fenda, escavada.

Comprimento (em mm). Macho: 2,70. Fêmea :2,90

Material examinado. Holótipo macho. BRASIL. Goiás: Aragarça, 29.III.1963, M. Alvarenga leg. (DZUP). Parátipos. Ibidem, 9 machos e 4 fêmeas. (DZUP).

Discussão. Espinho dorsal do pigóforo semelhante ao de A. fusca Oman, 1934 porém com a margem serreada. O edeago

1. Contribuição no 1354 do Departamento de Zoologia, Universidade Federal do Paraná.

2. Departamento de Zoologia, Universidade Federal do Paraná. Caixa Postal 19020, 81531-990 Curitiba-PR, Brasil.

3. Bolsista PIBIC/CNPq.

4. Bolsista do CNPq. 


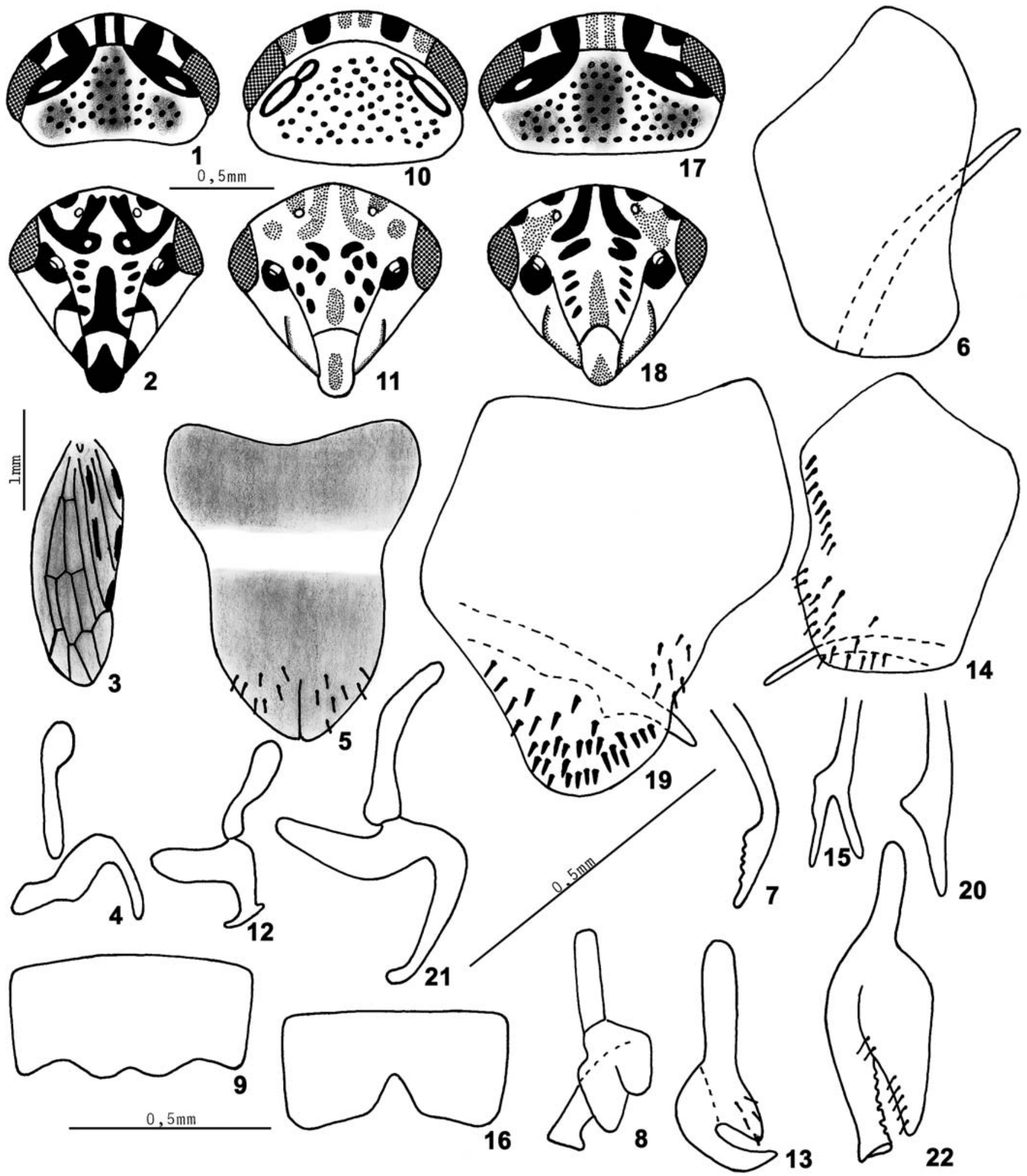

Figs. 1-9. Agalliana goianensis sp. nov. 1, cabeça e pronoto, dorsal; 2, face; 3, tégmina; 4, conetivo e edeago, lateral; 5, valva e placas subgenitais; 6, pigóforo, lateral; 7, espinho dorsal do pigóforo, visto de cima; 8, estilo; 9, sétimo esterno. Figs. 10-16. Agalliana alutacea sp. nov. 10, cabeça e pronoto, dorsal; 11, face; 12, conetivo e edeago, lateral; 13, estilo; 14, pigóforo, lateral; 15, espinho dorsal do pigóforo, visto de cima; 16, sétimo esterno. Figs. 17-22. Agalliana truncata sp. nov. 17, cabeça e pronoto, dorsal; 18, face; 19, pigóforo, lateral; 20, espinho dorsal do pigóforo, visto de cima; 21, conetivo e edeago, lateral; 22, estilo. 
apresenta o ápice arredondado enquanto que em $A$. fusca é bipartido.

\section{Agalliana alutacea sp. nov.}

(Figs. 10-16)

Holótipo macho. Coroa amarelada; margem anterior com duas manchas arredondadas, próximas aos olhos e duas faixas medianas, marrom-claras; disco com duas manchas arredondadas, pretas. Face amarelada. Frontoclípeo com nuanças marrom-claras; arcos laterais marrom-escuros e duas manchas, uma ovalada e outra em forma de "L" marrom-claras. Anteclípeo com uma mancha ovalada marrom-clara. Lora margeadas de marrom-claro. Genas com uma mancha marromescura contornando o alvéolos antenais.

Pronoto amarelado; margem anterior com duas manchas marrom-escuras; pontuações marrom-claras. Escutelo amarelado com nuanças marrons; triângulos basais marromescuros.

Tégminas marrom-claras. Venação marrom. Veias anais com áreas esbranquiçadas. Margem anal com manchas marromescuras.

Pigóforo com pequenas cerdas na margem ventro-apical; espinho dorsal forquilhado, com os braços do mesmo comprimento. Placas subgenitais com ápice arredondado. Edeago com a extremidade apical voltada para cima; um par de processos subapicais, espiniformes, voltados para trás.

Fêmea. Externamente semelhante ao macho. Sétimo esterno mais largo do que longo; margem posterior com uma fenda mediana como um " $V$ " invertido; margem posterior, lateral à fenda, sinuosa; superfície com uma mancha marrom escura junto à fenda.

\section{Comprimento ( em mm). Macho: 3,20. Fêmea: 3,40}

Material examinado. Holótipo macho. BRASIL. Mato Grosso: Nova Xavantina, 18.VIII. 1997, K. Zanol leg. (DZUP). Parátipos. Ibidem: 3 machos, 4 fêmeas; Chapada, XI.1963, M. Alvarenga leg., 2 fêmeas; Xavantina,VII.1962, Alvarenga-Oliveira leg., 2 fêmeas; Jacaré (P.N. Xingu), 25-30.XI.1965, M. Alvarenga leg., 1 fêmea. Goiás: Aragarça, 29.III.1963, M. Alvarenga leg., 5 machos, 4 fêmeas. (DZUP).

Variação intra-específica. Os machos de Aragarça, Goiás, são mais escuros. Coroa com manchas pretas. Face com manchas marrom-escuras. Pronoto marrom-escuro em quase toda sua extensão.
Discussão. O espinho dorsal do pigóforo é forquilhado como em A. sticticollis (Stal, 1859), porém os braços são do mesmo comprimento. O ápice do edeago é projetado dorsalmente e com um processo dentiforme ventral, enquanto em A. sticticollis o ápice é truncado e apresenta um espinho subapical na superfície ventral.

\section{Agalliana truncata sp. nov.}

(Figs. 17-22)

Holótipo macho. Coroa amarelada com quatro manchas arredondadas, pretas e duas faixas longitudinais marrom-claras. Face amarelada. Frontoclípeo com arcos laterais e uma mancha em forma de "L", pretos; uma faixa longitudinal mediana e uma mancha próxima aos ocelos, marrom-claras. Anteclípeo com uma mancha triangular marrom-clara. Lora margeadas de marrom-claro. Genas com uma mancha contornando os alvéolos antenais, preta.

Pronoto amarelo; margem anterior com duas manchas ovadalas, pretas; disco com uma faixa longitudinal e duas manchas arredondadas, pretas; pontuações pretas. Escutelo amarelo; triângulos basais e uma faixa longitudinal, pretos.

Tégminas marrom-claras. Venação marrom. Veias anais com áreas amarelas. Ápice do clavo amarelo. Margem anal com manchas marrom-escuras.

Pigóforo com pequenas cerdas apicais; espinho dorsal, visto de cima, aproximadamente no terço apical, expandido lateralmente de forma mais ou menos triangular. Placas subgenitais com ápice truncado. Edeago sem apêndice.

Comprimento ( em mm): 3,00.

Fêmea. Desconhecida.

Material examinado. Holótipo macho. BRASIL. Paraná: Jussara, 02.V.1998, K. Zanol leg. (DZUP).

Discussão. O espinho dorsal do pigóforo é semelhante ao de $A$. fusca Oman, 1934. O ápice do edeago é arredondado e levemente curvo para cima enquanto que, em $A$. fusca, o ápice é bipartido.

\section{REFERÊNCIA}

OMAN, P. W. 1933. A classification of North American agalian leafhoppers. Technical Bulletin 372: 1-94 